\title{
Implications of the clone by harvest interaction in the selection of sugarcane genotypes in a regionalized program
}

D.N.A. Cabral', J.A.R. Nunes', P.D.S. Cabral'2, J. Zuchi ${ }^{2}$ A.J. Raizer ${ }^{3}$ and T.O.M. De Paula ${ }^{4}$

${ }^{1}$ Departamento de Biologia, Universidade Federal de Lavras, Lavras, MG, Brasil

${ }^{2}$ Departamento de Agronomia, Instituto Federal Goiano, Rio Verde, GO, Brasil

${ }^{3}$ Departamento de Ciências Agrárias, Universidade Federal do Paraná, Curitiba, PR, Brasil

${ }^{4}$ Departamento de Melhoramento Genético de Cana-de-Açúcar, Centro de Tecnologia Canavieira, Piracicaba, SP, Brasil

Corresponding author: J.A.R. Nunes

E-mail: jarnunes@dbi.ufla.br

Genet. Mol. Res. 16 (2): gmr16029660

Received March 7, 2017

Accepted March 29, 2017

Published June 29, 2017

DOI http://dx.doi.org/10.4238/gmr16029660

Copyright $(C 2017$ The Authors. This is an open-access article distributed under the terms of the Creative Commons Attribution ShareAlike (CC BY-SA) 4.0 License.

\begin{abstract}
The recommendation of sugarcane clones depends on several factors, as the response or performance of the clones over different cuts or harvests. The clone by harvest interaction might be difficult to identify superior clones in the final stages of the sugarcane breeding program. Thus, the objective of this study was to investigate and describe the implications of the genotype by harvest interaction in the adaptability and stability of genotypes and delineation of mega-environments from a set of multi-environment trials. Fifteen clones and four checks were evaluated in eight environments. The trait TPH (tons of pol per hectare) was evaluated in two harvests (plant cane and ratoon cane) in 2010 and
\end{abstract}


2011. The joint analysis showed significance for harvest $(\mathrm{H})$, environment (E), and genotype (G) effects. The interactions GxE, ExH, GxH, and ExGxH were also significant. The last three-way interaction indicated the differential response of the genotypes over environments, and that it depends on the harvests. The overall mean of the trials was $12.77 \mathrm{TPH}$. The coefficient of variation was $8.70 \%$ and the selective accuracy was $98.63 \%$, indicating high experimental precision. The genotypes G4, G14, and G16 were statistically superior to the check varieties used; however, these genotypes did not show high stability as described by the additive main effects and multiplicative interaction method. There was a specific adaptation between the E7 and E5 environments and the G4 and G5 genotypes, respectively. In general, the grouping of the environments was inconsistent throughout the harvests, except for the E1 and E4 environments, which exhibited similarities for the different genotypes.

Key words: AMMI; Genotype by environment interaction; Saccharum spp; Mega-environment

\section{INTRODUCTION}

Sugarcane is grown in various Brazilian states in a wide diversity of soils and climates. The variety recommended for the areas of cultivation is a major concern of the breeding programs of this crop given that poor varietal choice combined with a large planting area may lead to losses in yield and, consequently, loss of profitability for rural businesses.

Thus, breeding programs for the crop use strategies such as regionalization of the initial stages of the breeding programs and, in the final stages, the testing of numerous combinations of localities, years, and harvests to isolate and better describe the effects of the genotype by environment (GxE) interaction. The GxE interaction occurs due to the inconsistency in the performance of the genotypes in various environments, resulting in different responses of the genotypes to the environmental changes (Moll and Stuber, 1974; Guerra, 2010). These changes can be attributed to the planting sites, years, crop cycle, soil fertility, seasons, etc. (Parfitt, 2000), leading to greater difficulty in identifying superior clones that combine high production and stability in diverse cultivation environments.

Another particularity in sugarcane is the need to assess the genotypes in several cuts or harvests (plant cane and ratoons). Then, there is a possibility to change the pattern of response of the genotypes in the environments difficulting the identification of the superior genotypes. These changes have physiological causes and they are associated with the resilience of the genotypes. This aspect has been related in other studies (Ramburan, 2011, 2014), but a more detailed description of its influence on selection has not been emphasized.

To minimize the risk of an erroneous recommendation, numerous methodologies have been applied to the study of the GxE interaction. For example, we can cite the following studies: Wrick (1965), who proposed the ecovalence method; Eberhart and Russell (1966), who described non-segmented linear regression models; Cruz et al. (1989), who used bisegmented linear regression; Toler (1990), who described a nonlinear regression model; Nunes et al. (2005), who performed graphical analysis of the data; as well as Annicchiarico (1992) and Lin and Binns (1988), among others. Nevertheless, multivariate methods are considered

Genetics and Molecular Research 16 (2): gmr16029660 
more informative and adequate to describe the GxE interaction. There are some multivariate methods as described by Peixoto et al (2016) and the additive main effects and multiplicative interaction (AMMI) method is the most often applied.

The AMMI method combines analysis of variance with analysis of principal components to proceed to the decomposition of the sum of squares and, consequently, separation of the variation that can be attributed to the effect of the GxE interaction from the variation that occurs due to noise (Gauch, 2013). According to Falconer and Mackay (1996), Gauch (2013), and Gauch and Zobel (1988), the AMMI method stands out because it models the GxE interaction in a more realistic way that is consistent with the multivariate nature of the phenomenon. This methodology also enables the graphic representation, in biplots, of the genotypic and environmental scores that result from the AMMI analysis. Given that the AMMI analysis is well justified, the graphic analysis becomes very informative given that it enables i) practical interpretations for improvement purposes (e.g., visualizing the interrelationships of the environments) and ii) possible specific adaptabilities of certain genotypes for specific environments.

Studies have demonstrated the efficiency of AMMI analysis in the stratification of genotypes and environments, as well as their interaction, in sugarcane. When studying the effect of the rainfall regime on the GxE interaction, Ramburan (2011) found strong environmental interaction factors. Fernandes Jr et al. (2013), Guerra (2010), Rosa (2008), and Silveira et al. (2012) identified interactions in sugarcane, thereby furthering the recommendation of highly responsive cultivars and reporting improvement in the yield in specific regions.

Thus, the objective of this study was to investigate and describe the implications of the genotype by harvest interaction in the adaptability and stability of genotypes and delineation of mega-environments from a set of multi-environment trials.

\section{MATERIAL AND METHODS}

The experiments were performed at eight locations that are part of the evaluation network of the Sugarcane Technology Center (Centro de Tecnologia Canavieira - CTC) in the Center-South region of Brazil: E1 - Araporã Bioenergia Mill, municipality of Araporã, MG; E2 - Jalles Machado Mill, municipality of Goianésia, GO; E3 - Nova Fronteira Mill, municipality of Quirinópolis, GO; E4 - Ipê Mill, municipality of Nova Independência, SP; E5 - Iturama Mill, municipality of Iturama, MG; E6 - Santa Adelia Mill, municipality of Pereira Barreto, SP; E7 - Gasa Mill, municipality of Andradina, SP; and E8 - Madhu Mill, municipality of Promissão, SP (Table 1).

\begin{tabular}{|c|c|c|c|c|c|c|}
\hline \multirow[t]{2}{*}{ Env. } & \multirow[t]{2}{*}{ Location } & \multirow[t]{2}{*}{ Planting date } & \multicolumn{2}{|c|}{ Harvest date } & \multirow[t]{2}{*}{ Soil $^{1}$} & \multirow[t]{2}{*}{ Prod. Env. $^{2}$} \\
\hline & & & Harvest 1 & Harvest 2 & & \\
\hline E1 & Araporã Bioenergia & $03 / 16 / 2009$ & $09 / 17 / 2010$ & $08 / 22 / 2011$ & \begin{tabular}{|l|} 
LVdfl.1. \\
\end{tabular} & B-IV \\
\hline E2 & Jalles Machado & $03 / 10 / 2009$ & $05 / 17 / 2010$ & $05 / 20 / 2011$ & \begin{tabular}{|l|} 
LVAd1.4 \\
\end{tabular} & $\mathrm{C}-\mathrm{V}$ \\
\hline E3 & Nova Fronteira & $03 / 18 / 2009$ & $09 / 27 / 2010$ & $08 / 24 / 2011$ & \begin{tabular}{|l|} 
LVdf1.1 \\
\end{tabular} & B-IV \\
\hline E4 & Ipê & $04 / 07 / 2009$ & $07 / 28 / 2010$ & $06 / 19 / 2011$ & LVe3.3 & C-III \\
\hline E5 & Iturama & $04 / 27 / 2009$ & $05 / 07 / 2010$ & $06 / 17 / 2011$ & LVd3.1 & D-IV \\
\hline E6 & Santa Adelia & $05 / 06 / 2009$ & $06 / 09 / 2010$ & $06 / 16 / 2011$ & \begin{tabular}{|l|} 
LVAd3.4 \\
\end{tabular} & D-III \\
\hline E7 & Gasa & $06 / 02 / 2009$ & $07 / 27 / 2010$ & $06 / 20 / 2011$ & \begin{tabular}{|l|} 
LVe3.1 \\
\end{tabular} & C-III \\
\hline E8 & Madhu & $03 / 27 / 2009$ & $07 / 21 / 2010$ & $07 / 05 / 2011$ & PVAd3.1 & C-II/III \\
\hline
\end{tabular}

${ }^{1}$ In accordance with the Brazilian classification of soils (EMBRAPA, 2006). ${ }^{2}$ Classification into production environments (Centro de Tecnologia Canavieira, 2012).

Genetics and Molecular Research 16 (2): gmr16029660 
The edaphoclimatic classification of the production environment was performed by the standards determined by the CTC (Table 1): A - an environment with high productive capacity, through $\mathrm{E}$ - an environment with low productive capacity. Climates were similarly classified from I - an environment with low climatic limitation, through VII - an environment with a very high climatic limitation.

Fifteen clones and four checks (CTC2, CTC4, RB867515, and SP813250) were evaluated in the first harvest (plant cane) and second harvest (first ratoon). The experiments were conducted in a randomized complete block design, with three replications. Each plot was composed of four rows, $20 \mathrm{~m}$ in length, with a spacing of $1.5 \mathrm{~m}$.

The trait evaluated was tons of pol per hectare (TPH), which was measured using the methodology described by Oliveira et al. (2008). Specifically, TPH $=($ TSH x PSS) / 100; where TSH is the tons of stalks per hectare, obtained by direct weighing of the plot via mechanized harvesting; PSS is the percentage of sucrose contained in the juice, obtained by the technological analysis of 10 stems 4 days before harvest.

We carried out analysis of variance of the data for each environment and harvest. The hypothesis of the homogeneity of the residual variances $\left(\mathrm{QM}_{\mathrm{R}}\right)$ was evaluated by the Hartley test. For the joint analysis of the MET trials involved in the two harvests, we adopted the following fixed model:

$y_{i j k}=\mu+e_{k}+b_{j(k)}+g_{i}+g e_{i k}+g b_{i j(k)}+h_{l}+b h_{j(k) l}+e h_{k l}+g h_{i l}+g e h_{i k l}+\varepsilon_{i j k l}$ (Equation 1)

where $y_{i j k}$ is the observation of the $\mathrm{i}$-th genotype in the $\mathrm{j}$-th block of the k-th environment in the 1-th harvest; $\mu$ is the intercept; $e_{k}$ is the effect of the $k$-th environment; $b_{j(k)}$ is the effect of the $\mathrm{j}$-th block in the $\mathrm{k}$-th environment; $\mathrm{g}_{\mathrm{i}}$ is the effect of the $\mathrm{i}$-th genotype; $\mathrm{ge}_{\mathrm{ik}}$ is the effect of the interaction of the $\mathrm{i}$-th genotype with the $\mathrm{k}$-th environment; $\mathrm{gb}_{\mathrm{ij}(\mathrm{k})}$ is the error related to the interaction of the $\mathrm{i}$-th genotype with the $\mathrm{j}$-th block in the $\mathrm{k}$-th environment; $\mathrm{h}_{1}$ is the effect of the 1-th harvest; $b_{j(k) l}$ is the error related to the interaction of the $\mathrm{j}$-th block of the $\mathrm{k}$-th environment with the 1-th harvest; $\mathrm{eh}_{\mathrm{kl}}$ is the effect of the interaction of the k-th environment with the 1-th harvest; $\mathrm{gh}_{\mathrm{il}}$ is the effect of the interaction of the $\mathrm{i}$-th genotype with the 1-th harvest; geh $_{\mathrm{ikl}}$ is the effect of the interaction between the i-th genotype and the k-th environment and the l-th harvest; and $\mathrm{e}_{\mathrm{ijk} \mathrm{l}}$ is the experimental error associated with the $\mathrm{y}_{\mathrm{ijk} \mathrm{l}}$, which is assumed to be independent, homoscedastic, and normally distributed.

The significance of the effects was measured using the F-Snedecor test. The experimental precision was assessed by the coefficient of experimental variation, and the selective accuracy was estimated according to Resende and Duarte (2007). Means of the genotypes were clustering by the Scott-Knott test at the 5\% probability level.

After performing the joint analysis of variance and detecting the significance of the interaction effects, the analysis of adaptability and stability was performed using the AMMI method for each harvest and average of harvests, in according to the following model (Gauch, 1988):

$$
y_{i k}=\mu+g_{i}+e_{k}+\sum_{n} \lambda_{n} \gamma_{i n} \delta_{k n}+\rho_{i k}+\varepsilon_{i k}
$$

where $y_{i k}$ is the mean observed for the $i$-th genotype in the $j$-th environment; $\mu$ is the overall mean; $g_{i}$ is the main effect of the genotype $i$; $e_{k}$ is the main effect of the environment $k ; 1_{n}$ is the singular value of the $\mathrm{n}$-th principal component associated with the GxE matrix (principal

Genetics and Molecular Research 16 (2): gmr16029660 
component analysis - PCA); $g_{\text {in }}$ is the eigenvector element associated with genotype $i$ for the $\mathrm{n}$-th PCA; $\mathrm{d}_{\mathrm{kn}}$ is the eigenvector element associated with the environment $\mathrm{k}$ for the $\mathrm{n}$-th PCA; $r_{i k}$ is the noise associated with the $\mathrm{e}_{\mathrm{ik}}$ effect; and $\mathrm{e}_{\mathrm{ik}}$ is the mean experimental error. The Gollob test (Gollob, 1968) was used to select the AMMI model, i.e., to define how many principal components are retained.

From the AMMI analyses, the scores were determined and the biplot graphs were generated. All analyses were performed using the R statistical software (R Core Team, 2015).

\section{RESULTS AND DISCUSSION}

The accuracy values for the first harvest trials were 0.65 to 0.97 (Table 2). According to Resende and Duarte (2007), these values are considered moderate to very high. For the second harvest, the accuracy had a lower range of variation ( 0.87 to 0.96$)$, and the experimental precision was considered high to very high. The estimates of the experimental coefficients of variation $\left(\mathrm{CV}_{\mathrm{e}}\right)$ for the TPH reinforced the experimental precision. For the first harvest, the estimate of the $\mathrm{CV}_{\mathrm{e}}$ was $10.18 \%$; in the second harvest, this estimate was $14.2 \%$ (Table 2). It is worth highlighting that the trait in question is quantitative and therefore highly influenced by environmental factors.

In Table 2, which shows the individual and joint analysis of variance, it is possible to observe a significant difference among environments (E), genotypes $(\mathrm{G})$, and for the interaction (GxE) in the first harvest, second harvest, and joint analyses (Table 2). These results indicate the existence of genetic variability for the trait TPH. Therefore, a more detailed study of the GxE interaction is necessary so that it can be isolated or interpreted, and its influence described on the selection of the best genotypes.

\begin{tabular}{|c|c|c|c|c|}
\hline \multirow[t]{2}{*}{ Source of variation } & \multirow[t]{2}{*}{ d.f. } & \multicolumn{3}{|c|}{ F-calculated } \\
\hline & & First harvest & Second harvest & Joint harvest \\
\hline Environments (E) & 7 & $61.69^{* *}$ & $67.99 * *$ & $79.11^{* *}$ \\
\hline Genotypes (G) & 18 & $47.00^{* *}$ & $36.17 * *$ & $36.9^{* *}$ \\
\hline Interaction GxE & 126 & $3.06^{* *}$ & $3.46^{* *}$ & $3.30 * *$ \\
\hline Harvest $(\mathrm{H})$ & 1 & - & - & $2473.77 * *$ \\
\hline Interaction ExH & 7 & - & - & $70.69^{* *}$ \\
\hline Interaction $\mathrm{HxG}$ & 18 & - & - & $48.87^{* *}$ \\
\hline Interaction ExGxH & 126 & - & - & $3.12^{* *}$ \\
\hline General mean & & 16.36 & 9.17 & 12.77 \\
\hline Minimum accuracy & & 0.65 & 0.87 & - \\
\hline Maximum accuracy & & 0.97 & 0.96 & - \\
\hline $\mathrm{CV}_{\mathrm{e}}(\%)$ & & 10.18 & 14.2 & 8.70 \\
\hline
\end{tabular}

**Significant differences at $1 \%$ probability according to the F-test.

The significant variation associated with the harvest (first $v s$ second harvests) may be partly explained by the edaphoclimatic effects associated with the harvest year, as well as by the genetic effect associated with the ratoon regrowth ability of the different genotypes. Various authors have described the existence of the interaction between harvest and genotype $(\mathrm{HxG})$, even finding interactions between the time of harvest and genotypes (Gilbert et al., 2006; Zhou et al., 2011; Ramburan, 2011, 2014).

When evaluating the TPH of 15 genotypes in 13 sites, Santos (2008) found significant differences for the harvest in all evaluated sites, in addition to a GxH interaction

Genetics and Molecular Research 16 (2): gmr16029660 
in 5 of the 13 sites evaluated. Raizer and Vencosky (1999) also found a strong interaction between genotypes and harvests at the clone level, noting that this was an important result for understanding the genetic values of the crop. The obtained results corroborate to the study carried out by Melo et al. (2006), in which the genotypes exhibited differential TPH values in different harvests.

To better understand the GxE interaction, the data were additionally analyzed using the AMMI method. By this analysis, the sum of the squares of the GxE interaction is split into variation retained by the principal component of the interaction. The main purpose of the AMMI analysis is to select models that explain the "pattern" related to the interaction, neglecting the "noise". According to Silva and Benin (2012), there is a greater presence of a "pattern" in the first two axes (PCAs), and there is a gradual increase in "noise" in the second axis due to the loss of degrees of freedom associated with the sum of squares of the GxE interaction, reducing the predictive power of the analysis. Thus, the graphic interpretation was performed considering only the biplots AMMI1 (PCA1 x variable) and AMMI2 (PCA1 x PCA2). Besides, the significance of the ExGxH interaction indicated the differential response of the genotypes over environments, and that it depends on the harvests (Ramburan, 2014) (Table 2). Then, to describe the response pattern of the genotype in each harvest, the AMMI analysis was accomplished for each harvest and at the average of harvests.

The first two principal components explained $54.39 \%$ of the variation in the GxE interaction in the first harvest (38.4\% in the first IPCA and $19.99 \%$ in the second) and $67.70 \%$ of the variation in the GxE interaction in the second harvest $37.07 \%$ in the first IPCA and $30.63 \%$ in the second). For the average of the two harvests $63 \%$ of the GxE interaction was obtained (44.1\% in the first IPCA and $19.5 \%$ in the second). When evaluating the TPH at the average of the two harvests, Silveira et al. (2012) found that the first axis explained 56.78\% of the variation $(34.36 \%$ in the first axis and $22.42 \%$ in the second axis). Guerra (2010), also evaluating the TPH, found similar values $(59.44 \%$ in the first harvest and $54.22 \%$ in the second harvest). The author comments that although Gauch (1988) considers the values to be low, the higher concentration of the pattern partitioning in the first two axes makes the use of the AMMI two-dimensional graphical model acceptable.

In the analysis by the AMMI1 model, the abscissa represents the main effects (mean TPH of the genotypes and environments), while the ordinate represents the scores of the first principal component of the interaction (PCA1). Thus, the genotypes with values close to the ordinate (i.e., close to zero) will be the most stable within the tested environments given that they contribute less to the GxE interaction (Silveira et al., 2012; Fernandes Jr et al., 2013). In the AMMI2 model (PCA1 x PCA2), the genotypes close to the origin of the axes are more stable than those that are more distant because they contributed little to the magnitude of the GxE interaction. These models are widely used to demonstrate the behavior of genotypes in environments as well as to verify their productive potential graphically and to distinguish productive environments.

Thus, through the biplot of the AMMI1 model (Figure 1A), genotypes G8, G17, G19 (SP81 3250), G3, and G5 can be identified as being stable for the first harvest. However, only G3 and G5 were shown to have productive potential because they had a higher mean than the others. Clone G4 had the highest yield in the first harvest; however, it had lower stability than G3 and G5. Genotypes G14, G12, G1 (CTC2), and G16 also had high mean yields; however, they had medium stability (Figure 1A).

Genetics and Molecular Research 16 (2): gmr16029660 

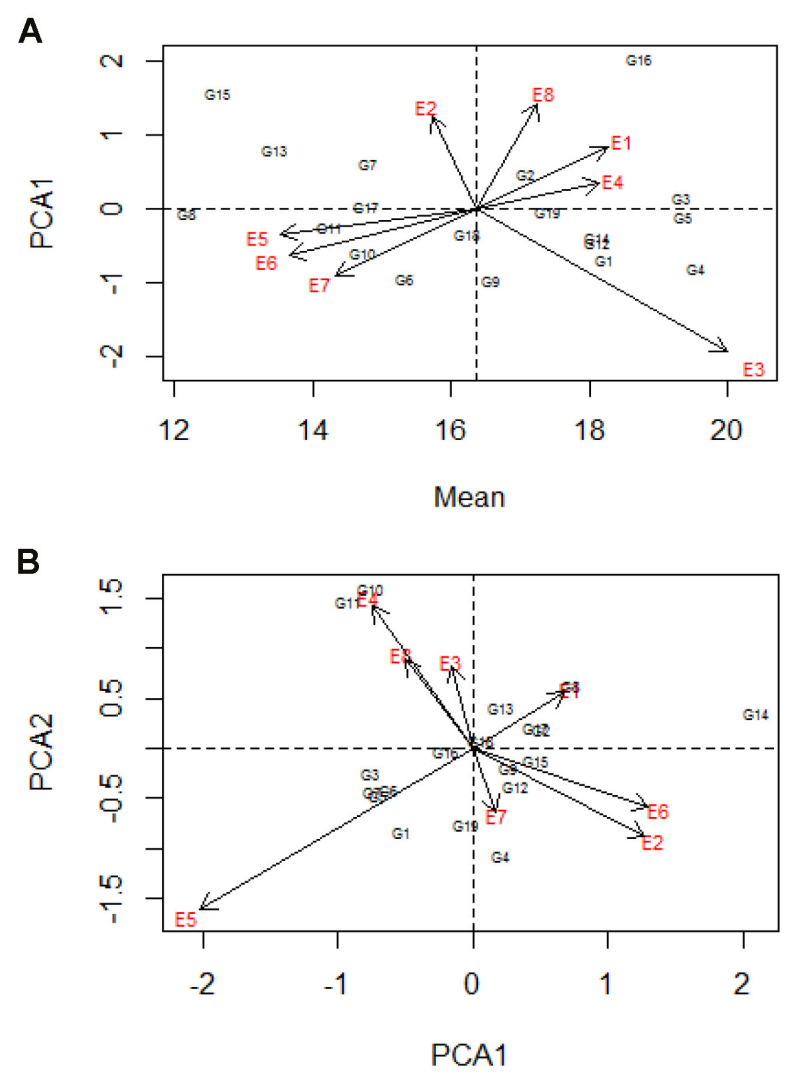

Figure 1. Graphical representation of the scores of the AMMI1 (A), and AMMI2 (B) models for the TPH trait in the first harvest of 19 genotypes evaluated in eight environments in the 2009/2010 crop.

Based on the biplot of the AMMI2 model (Figure 1B) for the TPH data, it can be seen that genotype G17 had high phenotypic stability in the first harvest. On the other hand, genotypes G14, G11, and G10 were the most unstable. Among the genotypes that had a high mean yield, the one with the greatest stability was G5, followed by G12 and G14. Regarding specific adaptability, the positive interaction between the genotypes G10 and G11 with the environment E6 can be highlighted.

Rea et al. (2011) reported that i) vectors of the environment with angles smaller than $90^{\circ}$ indicate environments with a similar influence on genotypes; ii) angles close to $90^{\circ}$ indicate no correlation between the environments; and iii) angles close to $180^{\circ}$ indicate a strong opposite relationship. However, as the objective of the study was to identify strong associations in the distinction of the genotypes, environments with angles of up to approximately $25^{\circ}$ were considered similar.

Thus, among the environments, E3, E1, and E4 had the highest yield means, while E5, E6, and E7 were the less productive (Figure 1A). The environments E3, E4, E7, and E8 were the most stables. The environments with more contribution to the interaction were E4 and E5 (Figure 1B). For the first harvest, there was a similarity in the genotype ordering between environments: E2 and E6, and E3, E8, and E4 (Figure 1B). 
In the second harvest (Figure 2A), the AMMI1 analysis demonstrated that G3, G4, G2, G5, and G12 associated high mean yield and medium and high stability. Genotypes G3, G4, and G5 had higher mean yields than all the check varieties - G1 (CTC2), G2 (CTC4), G18 (RB867515), and G19 (SP813250). G16 had a large decline in yield from the first harvest $(18.74 \mathrm{t} / \mathrm{ha})$ to the second harvest $(8.44 \mathrm{t} / \mathrm{ha})$, which may be associated with the low ratoon sprouting capacity of the clone. The check varieties G18 (RB867515) and G19 (SP813250) had good stability both in the plant cane and in the ratoon as well as a good mean yield. Thus, these varieties should be further considered in future study.
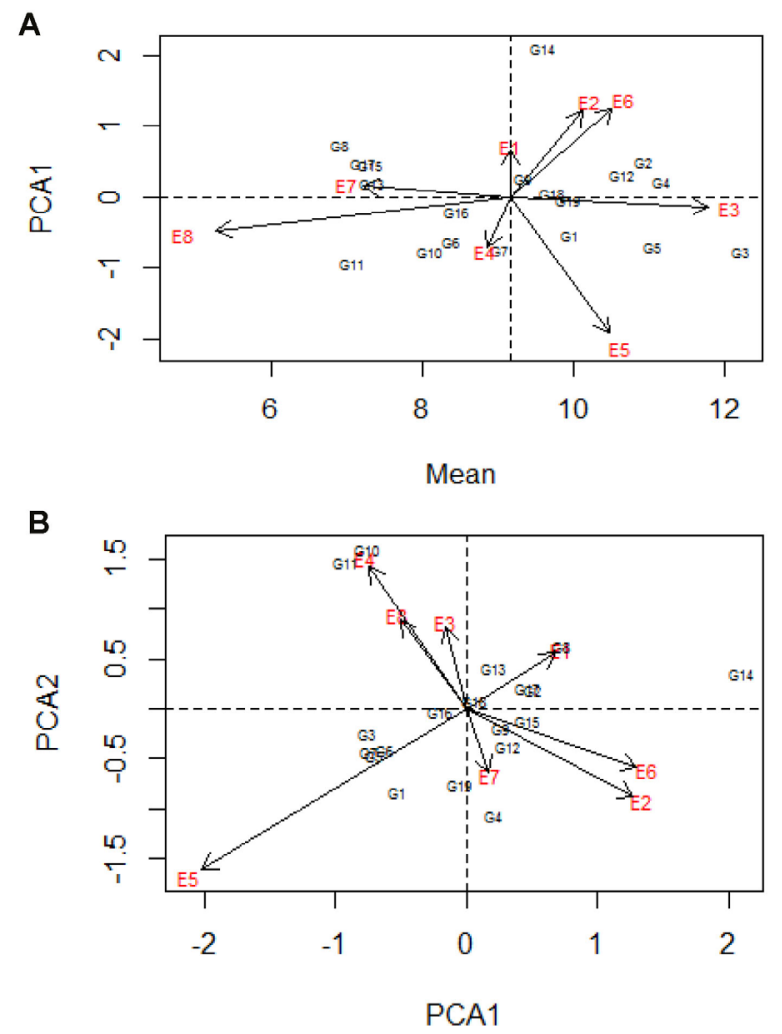

Figure 2. Graphical representation of the scores of A. AMMI1 (PCA1 vs TPH) and B. AMMI2 (PCA1 vs PCA2) models for the TPH variable in the second harvest of 19 genotypes evaluated in eight environments in the 2009/2010 crop.

In the second harvest, the genotypes G10 and G11 showed specific adaptability with the environments E4, E8, and E3 (Figure 2B). The specific adaptability between G4 and E7 had already occurred in the first harvest, indicating that this effect may be stable throughout harvests.

A high variation was observed in the behavior of the environments (E1, E8, E6, E4, and E5), an effect that may be associated with large climatic variations between the locations and years. The E3 environment had a high mean yield in both the first and second harvests, while the E7 environment had a low yield in both harvests (Figures 1A and 2A). The most stable environment was E7, while the most unstable were E5, E4, E6, and E2. The environments E4

Genetics and Molecular Research 16 (2): gmr16029660 
and E5 had very different results compared to the first harvest. The E2 environment again had high instability, as in the first harvest (Figure 2A and B).

In the second harvest, there was a similarity in the genotype ordering among environments E6, E2, and E7 (Figure 2B). A similarity was also verified between environments $\mathrm{E} 4, \mathrm{E} 8$, and E3; only the environments E6 and E7 were similar in the two harvests.

From the AMMI1 biplot, considering the mean of the two harvests (plant cane and first ratoon), genotypes G8, G6, G7, G18, and G5 can be seen as very stable. However, only genotypes G4, G14, and G16 (14.43, 14.53, and 14.95 t/ha TPH, respectively) had means above that of the main control (SP813250) - 13.66 t/ha TPH (Figure 3A). The G18 (RB867515) check variety had high stability and was indicated as a good orientation point in the trials, primarily in the initial phases of the program. The check varieties G1 (CTC2), G2 (CTC4), and G19 (SP813250) had high mean yields but moderate stabilities.
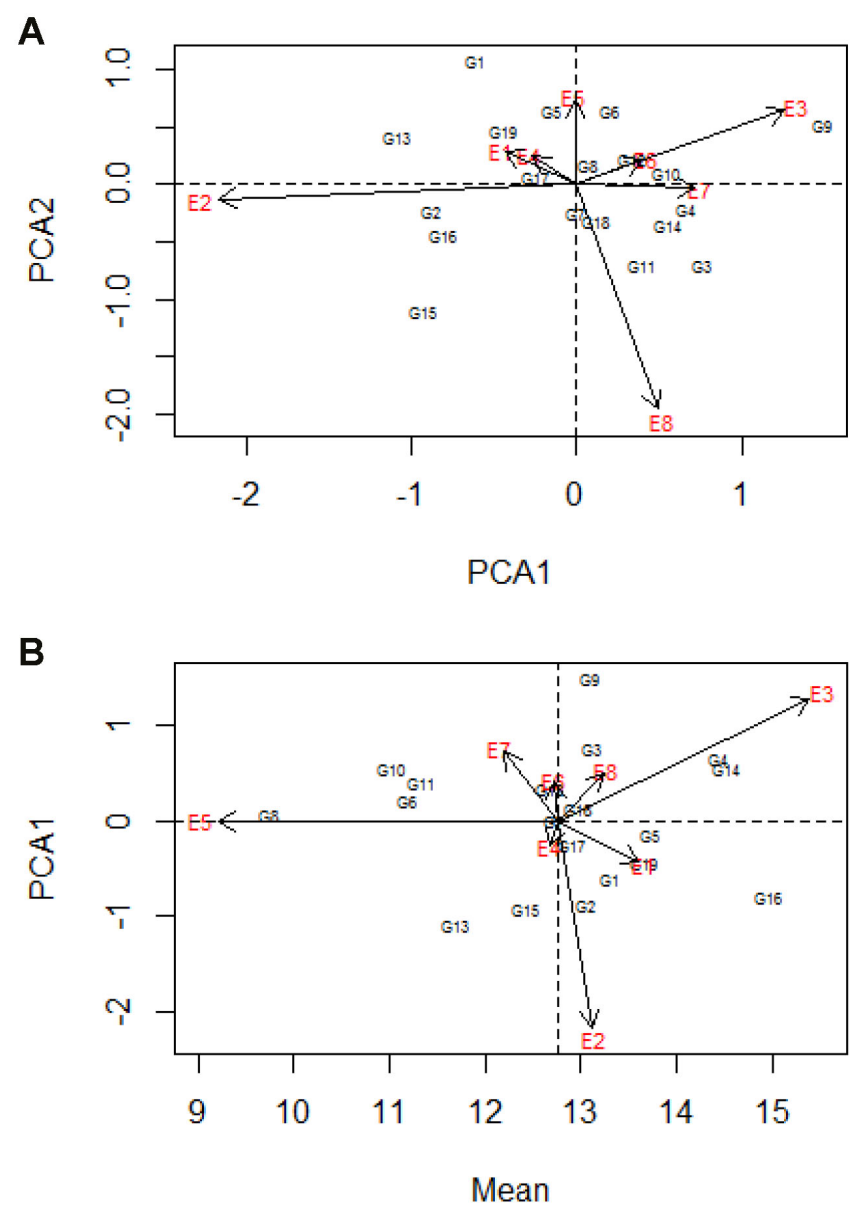

Figure 3. Graphical representation of the scores of A. AMMI1 (PCA1 vs TPH) and B. AMMI2 (PCA1 vs PCA2) models for the TPH variable in the mean of the two harvests of 19 genotypes evaluated in eight environments in the $2009 / 2010$ crop.

Genetics and Molecular Research 16 (2): gmr16029660 
From AMM2 biplot, genotypes G8, G17, G7, and G18 can be observed as the most stable, while genotypes G9, G15, G1, and G13 were the most unstable. The environments E4 and E5 were the most stable and might be good options for the development of initial phases of the program; however, more detailed studies should be conducted to confirm this trend. The environments E2, E3, and E8 were the most unstable. There were similarities in the description of the genotypes between environments E6 and E3, as well as between E1 and E4. The E1 and E4 environments were similar in the two harvests, and if this trend is confirmed, one of the sites can be maintained, thus reducing operating costs.

The characteristic patterns of the genotypes were very different between the first and second harvests (plant cane and ratoon), with some exceptions. It is important to note that we have better information than previous studies and that the analyses of sugarcane make use of more harvests. The G16 genotype exemplifies how much the mean can mask the overall performance of the crop. Specifically, despite having high performance in the first harvest, the potential of G16 was drastically reduced in the second harvest due to its low ratoon sprouting. However, in the mean of the two harvests, this genotype maintained high productive performance, which could lead to an erroneous recommendation. The adoption of more harvests makes the data obtained more reliable, thus enabling a more conclusive recommendation.

\section{Conflicts of interest}

The authors declare no conflict of interest.

\section{ACKNOWLEDGMENTS}

Research supported by Sugarcane Tecnological Center - "CTC", in association with Araporã Bioenergy, Jalles Machado, Nova Fronteira Bioenergy, Ipê, Iturama, Santa Adelia, Gasa, and Madhu.

\section{REFERENCES}

Annicchiarico P (1992). Cultivar adaptation and recommendation from alfalfa trials in Northern Italy. J. Genet. Breed. 46: 269-278.

Centro de Tecnologia Canavieira (2012). Censo Varietal e de Produtividade. Available at [http://www.ctcanavieira.com. br/downloads/Censo2012.pdf]. Accessed February 20, 2017.

Cruz CD, Torres RA and Vencovsky R (1989). An alternative approach to the stability analysis proposed by Silva and Barreto. Rev. Bras. Genet. 12: 567-580.

Eberhart SA and Russell WA (1966). Stability parameters for comparing varieties. Crop Sci. 6: 36-40. http://dx.doi. org/10.2135/cropsci1966.0011183X000600010011x

EMBRAPA (2006). Centro Nacional de Pesquisa de Solos. Sistema brasileiro de classificação de solos. 2nd edn. Rio de Janeiro.

Falconer DS and Mackay TFC (1996). Introduction to quantitative genetics. 4th edn. Longman, Malaysia.

Fernandes Jr AR, Andrade JAC, Santos PC, Hoffmann HP, et al. (2013). Adaptabilidade e estabilidade de clones de canade-açúcar. Bragantia 72: 208-216. http://dx.doi.org/10.1590/brag.2013.033

Gauch Jr HG (1988). Model selection and validation for yield trials with interaction. Biometrics 44: 705-715. http://dx.doi. org $/ 10.2307 / 2531585$

Gauch Jr HG (2013). A simple protocol for AMMI analysis of yield trials. Crop Sci. 53: 1860-1869. http://dx.doi. org/10.2135/cropsci2013.04.0241

Gauch Jr HG and Zobel RW (1988). Predictive and postdictive success of statistical analyses of yield trials. Theor. Appl. Genet. 76: 1-10. http://dx.doi.org/10.1007/BF00288824

Genetics and Molecular Research 16 (2): gmr16029660 
Gilbert RA, Shine Jr JM, Miller JD, Rice RW, et al. (2006). The effect genotype, environment and time of harverst on sugarcane fields in Florida, USA. Field Crops Res. 95: 156-170. http://dx.doi.org/10.1016/j.fcr.2005.02.006

Gollob HFA (1968). A statistical model which combines features of factor analytic and analysis of variance techniques. Psychometrika 33: 73-115. http://dx.doi.org/10.1007/BF02289676

Guerra EP (2010). Avaliação da adaptabilidade e estabilidade de clones precoces de cana-de-açúcar (Saccharum spp.). Doctoral thesis, Universidade Federal do Paraná, UFPR, Curitiba.

Lin CS and Binns MRA (1988). A method of analyzing cultivar x location x year experiments: a new stability parameter. Theor. Appl. Genet. 76: 425-430. http://dx.doi.org/10.1007/BF00265344

Melo LJOT, Oliveira FJ, Bastos GQ, Filho CJA, et al. (2006). Interação genótipo x ciclos de colheita de cana-de-açúcar da Zona da Mata Norte de Pernambuco. Bragantia 65: 197-205. http://dx.doi.org/10.1590/S0006-87052006000200002

Moll RH and Stuber CW (1974). Quantitative genetics-empirical results relevant to plant breeding. Adv. Agron. 26: $277-$ 313. http://dx.doi.org/10.1016/S0065-2113(08)60874-3

Nunes JAR, Ramalho MAP and Abreu AFB (2005). Graphical method in studies of adaptability and stability of cultivars. Annu. Rep. Bean Improv. Coop. 48: 182-183.

Oliveira RA, Daros E, Bespalhok-Filho JC, Zambon JLC, et al. (2008). Seleção de famílias de cana-de-açúcar via modelos mistos. Scientia Agraria 9: 269-274. http://dx.doi.org/10.5380/rsa.v9i3.11564

Parfitt RC (2000). Genotype by environment interaction among secondary variety trials in the northern region of the South African sugar industry. Proc. S. Afr. Sug. Technol. Ass. 74: 245-248.

Peixoto LS, Nunes JAR and Furtado DF (2016). Factor analysis applied to the G+GE matrix via REML/BLUP for multienvironment data. Crop Breed. Appl. Biotechnol. 16: 1-6. http://dx.doi.org/10.1590/1984-70332016v16n1a1

R Core Team (2015). R: A language and environment for statistical computing. R Foundation for Statistical Computing, Vienna, Austria. URL https://www.R-project.org/.

Raizer AJ and Vencovsky R (1999). Estabilidade fenotípica de novas variedades de cana-de-açúcar para o estado de São Paulo. Pesq. Agropec. Bras. 34: 2241-2246.

Ramburan SA (2011). Sugarcane cultivar X time of harvest interactions in South África. Plant Soil 28: 75-84. http://dx.doi. org/10.1080/02571862.2011.10640016

Ramburan SA (2014). Multivariate illustration and interpretation of non-repeatable genotype X environment interactions in sugarcane. Field Crops Res. 157: 57-64. http://dx.doi.org/10.1016/j.fcr.2013.12.009

Rea R, Sousa-Vieira O, Ramón M, Alejos G, et al. (2011). AMMI analysis and its application to sugarcane regional trials in Venezuela. Sugar Tech. 13: 108-113. http://dx.doi.org/10.1007/s12355-011-0070-8

Resende MDV and Duarte JB (2007). Precisão e controle de qualidade em experimentos de avaliação de cultivares. Pesqui. Agropecu. Trop. 37: 182-194.

Rosa CO (2008). Interação de genótipos de cana-de-açúcar com ambientes no Estado de Goiás. Doctoral thesis, Universidade Federal de Goiás, UFG, Goiânia.

Santos EGD (2008). Interação genótipos x locais em cana-de-açúcar e perspectivas de estratificação ambiental. Doctoral thesis, Escola Superior de Agricultura "Luiz de Queiroz", USP, Piracicaba.

Silva RR and Benin G (2012). Análises Biplot: conceitos, interpretações e aplicações. Cienc. Rural 42: 404-1412. http:// dx.doi.org/10.1590/S0103-84782012000800012

Silveira LCI, et al. (2012). Adaptabilidade e estabilidade fenotípica de genótipos de cana-de-açúcar no Estado de Minas Gerais. Cienc. Rural 42: 587-593. http://dx.doi.org/10.1590/S0103-84782012000400002

Toler JE (1990). Patterns of genotype performance over environmental arrays. Doctoral thesis, Clemson University, Clemson.

Wrick G (1965). Zur berechning der okovalens bei sommerweizen und hafer. Pfanzenzuchtung 52: 127-138.

Zhou M, Joshi S, Maritz T and Koberstein H (2011). Components of genotype by environment interaction among SASRI regional breeding and selection programmes and their implications. Proc. S. Afr. Sug. Technol. Ass. 84: 363-374.

Genetics and Molecular Research 16 (2): gmr16029660 